\title{
Agata Girul
}

Urząd Statystyczny we Wrocławiu (Statistical Office in Wrocław)

e-mail: A.Girul@stat.gov.pl

MAJOR SOCIO-ECONOMIC DATA ON VOIVODESHIPS

\begin{tabular}{|c|c|c|c|c|}
\hline \multicolumn{2}{|l|}{$\begin{array}{l}\text { WYSZCZEGÓLNIENIE } \\
\text { SPECIFICATION }\end{array}$} & \multirow{2}{*}{\begin{tabular}{|r} 
Dolnośląskie \\
19947
\end{tabular}} & \multirow{2}{*}{$\begin{array}{r}\text { Opolskie } \\
9412\end{array}$} & \multirow{2}{*}{\begin{tabular}{|r} 
Śląskie \\
12333
\end{tabular}} \\
\hline Powierzchnia $\mathrm{w} \mathrm{km}^{2}$ & 2010 & & & \\
\hline Area in $\mathrm{km}^{2}$ & 2015 & 19947 & 9412 & 12333 \\
\hline & 2016 & 19947 & 9412 & 12333 \\
\hline 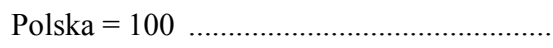 & 2010 & 6,4 & 3,0 & 3,9 \\
\hline Poland $=100$ & 2015 & 6,4 & 3,0 & 3,9 \\
\hline & 2016 & 6,4 & 3,0 & 3,9 \\
\hline $\begin{array}{l}\text { Zużycie wody na potrzeby gospodarki } \\
\text { narodowej i ludności na } 1 \mathbf{k m}^{2} \mathrm{w} \text { dam }^{3}\end{array}$ & 2010 & 21,3 & 11,7 & 32,5 \\
\hline Consumption of water for needs of the & 2015 & 19,8 & 13,0 & 30,6 \\
\hline $\begin{array}{l}\text { national economy and population } \\
\text { per } 1 \mathbf{k m}^{2} \text { in dam }\end{array}$ & 2016 & 20,2 & 14,0 & 30,1 \\
\hline $\begin{array}{l}\text { Ludność korzystająca z oczyszczalni } \\
\text { ścieków w \% ludności ogółem .................... }\end{array}$ & 2010 & 75,9 & 66,5 & 72,0 \\
\hline Population connected to wastewater & 2015 & 79,7 & 74,5 & 80,2 \\
\hline treatment plants in $\%$ of total population & 2016 & 80,7 & 76,0 & 80,7 \\
\hline $\begin{array}{l}\text { Odpady komunalne zebrane } \\
\text { na } 1 \text { mieszkańca } \mathrm{w} \text { kg .......................... }\end{array}$ & 2010 & 341 & 255 & 298 \\
\hline $\begin{array}{l}\text { Municipal waste collected per capita } \\
\text { in } \mathrm{kg}\end{array}$ & 2015 & 340 & 279 & 332 \\
\hline & 20156 & 361 & 296 & 355 \\
\hline $\begin{array}{l}\text { Nakłady na środki trwałe (ceny bieżące) } \\
\text { w \% nakładów inwestycyjnych ogółem: } \\
\text { Outlays on fixed assets (current prices) } \\
\text { in \% of total investment outlays: }\end{array}$ & & & & \\
\hline służące ochronie środowiska ...................... & 2010 & 3,9 & 7,0 & 5,6 \\
\hline in environmental protection & 2015 & 5,2 & 5,1 & 6,8 \\
\hline & 2016 & 1,4 & 3,3 & 3,9 \\
\hline służące gospodarce wodnej . & 2010 & 1,6 & 1,5 & 0,8 \\
\hline in water management & 2015 & 2,7 & 3,0 & 1,5 \\
\hline & 2016 & 1,6 & 1,8 & 1,0 \\
\hline
\end{tabular}




\begin{tabular}{|c|c|c|c|c|c|}
\hline & & & & & rata Girul \\
\hline $\begin{array}{r}\text { ŚLASSKI } \\
\text { PRZEGLAD }\end{array}$ & & & & & \\
\hline STATYSTYCZNY & $\begin{array}{c}\text { WYSZCZEGÓLNIENIE } \\
\text { SPECIFICATION }\end{array}$ & & Dolnośląskie & Opolskie & Śląskie \\
\hline Nr 16(22) & Ludność $^{1}$ (stan w dniu 31 XII): & & & & \\
\hline & $\begin{array}{l}\text { Population }{ }^{1} \text { (as of } 31 \text { XII): } \\
\text { w tysiącach }\end{array}$ & 2010 & 2917,2 & 1017,2 & 4634,9 \\
\hline & in thousand & 2015 & 2904,2 & 996,0 & 4570,8 \\
\hline & & 2016 & 2903,7 & 993,0 & 4559,2 \\
\hline & Polska $=100$ & 2010 & 7,6 & 2,6 & 12,0 \\
\hline & Poland $=100$ & 2015 & 7,6 & 2,6 & 11,9 \\
\hline & & 2016 & 7,6 & 2,6 & 11,9 \\
\hline & $\mathrm{w}$ miastach $\mathrm{w} \%$. & 2010 & 69,9 & 52,4 & 77,8 \\
\hline & in urban areas in \% & 2015 & 69,2 & 51,9 & 77,1 \\
\hline & & 2016 & 69,0 & 51,9 & 77,0 \\
\hline & na $1 \mathrm{~km}^{2}$. & 2010 & 146 & 108 & 376 \\
\hline & per $1 \mathrm{~km}^{2}$ & 2015 & 146 & 106 & 371 \\
\hline & & 2016 & 146 & 106 & 370 \\
\hline & Kobiety na 100 mężczyzn ......... & 2010 & 108 & 107 & 107 \\
\hline & Females per 100 males & 2015 & 108 & 107 & 107 \\
\hline & & 2016 & 108 & 107 & 107 \\
\hline & Ludność wedlug grup wieku w \%: & & & & \\
\hline & Population by age groups in \%: & & & & \\
\hline & 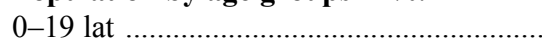 & 2010 & 19,9 & 19,8 & 19,8 \\
\hline & & 2015 & 18,8 & 18,1 & 18,8 \\
\hline & & 2016 & 18,7 & 17,9 & 18,7 \\
\hline & 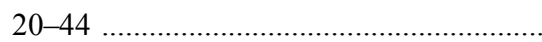 & 2010 & 37,3 & 37,6 & 37,0 \\
\hline & & 2015 & 37,4 & 36,9 & 36,3 \\
\hline & & 2016 & 37,2 & 36,5 & 36,1 \\
\hline & $45-64$. & 2010 & 29,5 & 28,4 & 29,0 \\
\hline & & 2015 & 27,6 & 28,6 & 28,2 \\
\hline & & 2016 & 27,1 & 28,5 & 27,9 \\
\hline & 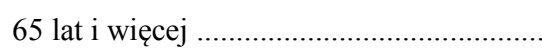 & 2010 & 13,3 & 14,2 & 14,2 \\
\hline & and more & 2015 & 16,2 & 16,4 & 16,7 \\
\hline & & 2016 & 17,0 & 17,1 & 17,3 \\
\hline & Ruch naturalny: & & & & \\
\hline & Vital statistics: & & & & \\
\hline & Małżeństwa na 1000 ludności ..................... & 2010 & 5,6 & 5,6 & 6,1 \\
\hline & Marriages per 1000 population & 2015 & 4,5 & 4,9 & 4,9 \\
\hline & & 2016 & 4,8 & 4,9 & 5,0 \\
\hline & 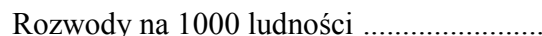 & 2010 & 2,0 & 1,5 & 1,8 \\
\hline & Divorces per 1000 population & 2015 & 1,9 & 1,7 & 1,8 \\
\hline & & 2016 & 1,7 & 1,4 & 1,8 \\
\hline & Rozwody na 1000 zawartych małżeństw .... & 2010 & 354 & 266 & 299 \\
\hline & Divorces per 1000 marriages contracted & 2015 & 419 & 341 & 369 \\
\hline & & 2016 & 366 & 297 & 356 \\
\hline & Płodność kobiet & 2010 & 41,3 & 35,4 & 41,7 \\
\hline & Female fertility & 2015 & 38,1 & 34,3 & 38,7 \\
\hline & & 2016 & 40,1 & 36,3 & 40,2 \\
\hline
\end{tabular}

${ }^{1}$ Od 2010 r. dane prezentowane są w oparciu o wyniki NSP 2011.

Since 2010 data presented on the basis of Population and Housing Census 2011. 


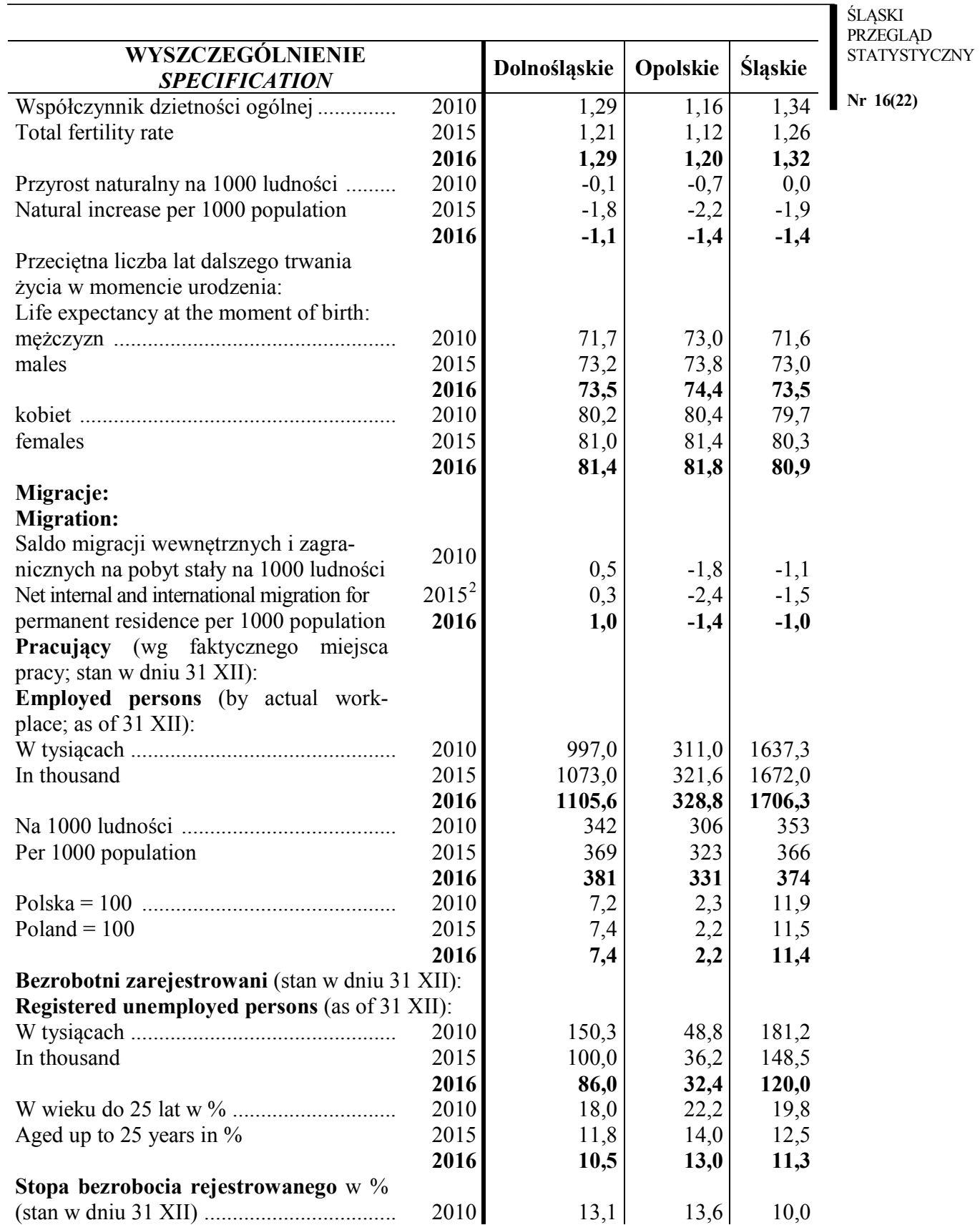

${ }^{2}$ Do obliczeń salda wykorzystano dane o migracjach wewnętrznych za 2015 r. i migracjach zagranicznych za $2014 \mathrm{r}$.

For calculating net migration, data on internal migration for 2015 and data on international migration for 2014 were used. 


\begin{tabular}{|c|c|c|c|c|c|}
\hline & & & & & gata Girul \\
\hline $\begin{array}{r}\text { ŚLASKI } \\
\text { PRZEGLAAD }\end{array}$ & & & & & \\
\hline STATYSTYCZNY & $\begin{array}{l}\text { WYSZCZEGÓLNIENIE } \\
\text { SPECIFICATION }\end{array}$ & & Dolnośląskie & Opolskie & Śląskie \\
\hline Nr 16(22) & Registered unemployment rate in \% & 2015 & 85 & 101 & 82 \\
\hline & & 2016 & $\begin{array}{l}0,5 \\
7,2\end{array}$ & $\begin{array}{r}10,1 \\
9,0\end{array}$ & $\begin{array}{l}8,2 \\
6,6\end{array}$ \\
\hline & $\begin{array}{l}\text { Przeciętne miesięczne wynagrodzenia } \\
\text { brutto: } \\
\text { Average monthly gross wages and sala- } \\
\text { ries: }\end{array}$ & & & & \\
\hline & 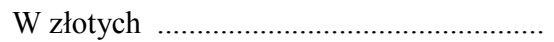 & 2010 & 3211,80 & 2946,59 & 3306,69 \\
\hline & In zlotys & 2015 & 3960,48 & 3565,04 & 3969,67 \\
\hline & & 2016 & 4140,76 & 3708,24 & 4059,14 \\
\hline & Polska $=100$ & 2010 & 99,6 & 91,4 & 102,6 \\
\hline & Poland $=100$ & 2015 & 101,3 & 91,2 & 101,6 \\
\hline & & 2016 & 102,2 & 91,5 & 100,2 \\
\hline & $\begin{array}{l}\text { Przeciętny miesięczny dochód rozpo- } \\
\text { rządzalny na } 1 \text { osobę w gospodar- } \\
\text { stwach domowych }{ }^{3} \text { w zł }\end{array}$ & 2010 & 1251,94 & 1118.53 & 1183.88 \\
\hline & Average monthly per capita available & 2015 & 1471,84 & 1288,74 & 1420,54 \\
\hline & income of households ${ }^{3}$ in $\mathrm{zl}^{2}$ & 2016 & 1586,03 & 1389,92 & 1513,23 \\
\hline & $\begin{array}{l}\text { Przeciętne miesięczne wydatki na } \\
1 \text { osobę w gospodarstwach domowych }\end{array}$ & & & & \\
\hline & 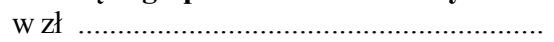 & 2010 & 1037,20 & 1023,67 & 1023,66 \\
\hline & $\begin{array}{l}\text { Average monthly per capita expendi- } \\
\text { tures }\end{array}$ & 2015 & 1178,66 & 1102,99 & 1136,42 \\
\hline & of households ${ }^{3}$ in $\mathrm{zl}$ & 2016 & 1211,59 & 1195,04 & 1202,37 \\
\hline & $\begin{array}{l}\text { Wskaźniki zagrożenia ubóstwem w \% } \\
\text { ogółu osób w gospodarstwach domo- } \\
\text { wych - o wydatkach poniżej: } \\
\text { At-risk of poverty rates in \% of total } \\
\text { persons in households - with expenditures } \\
\text { below: }\end{array}$ & & & & \\
\hline & 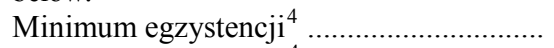 & 2010 & 5,3 & 3,6 & 4,5 \\
\hline & Subsistence minimum ${ }^{4}$ & 2015 & 4,0 & 6,5 & 3,4 \\
\hline & & 2016 & 2,9 & 5,2 & 3,0 \\
\hline & Relatywnej granicy ubóstwa ${ }^{5}$ & 2010 & 16,0 & 13,8 & 14,0 \\
\hline & Relative poverty threshold ${ }^{5}$ & 2015 & 11,9 & 13,7 & 10,7 \\
\hline & & 2016 & 10,5 & 10,6 & 10,3 \\
\hline
\end{tabular}

${ }^{3}$ Zob. przypis 1 .

See footnote 1 .

${ }^{4}$ Minimum egzystencji uznaje się za granicę ubóstwa skrajnego. Za punkt wyjścia ustalenia granic ubóstwa skrajnego przyjmuje się poziom minimum egzystencji obliczany przez Instytut Pracy i Spraw Socjalnych dla 1-osobowego gospodarstwa pracowniczego.

The subsistence minimum is recognized to be the extreme poverty line. The starting point adopted for determination of the extreme poverty line is subsistence minimum estimated by the Institute of Labour and Social Studies for 1-person employee's household.

${ }^{5}$ Ustalonej na poziomie 50\% średnich miesięcznych wydatków ekwiwalentnych gospodarstw domowych.

Set at $50 \%$ of the mean equivalised monthly household expenditures. 




${ }^{6}$ Kwota, która zgodnie z obowiązującą ustawą o pomocy społecznej uprawnia do ubiegania się o przyznanie świadczenia pieniężnego z systemu pomocy społecznej.

The amount, which according to the social assistance act provides eligibility for a monetary benefit from social assistance.

${ }^{7} \mathrm{~W} 2010 \mathrm{r}$. - łącznie z prokuraturą.

In 2010 - including prosecutor's office.

${ }^{8}$ Patrz przypis 1 .

See footnote 1. 


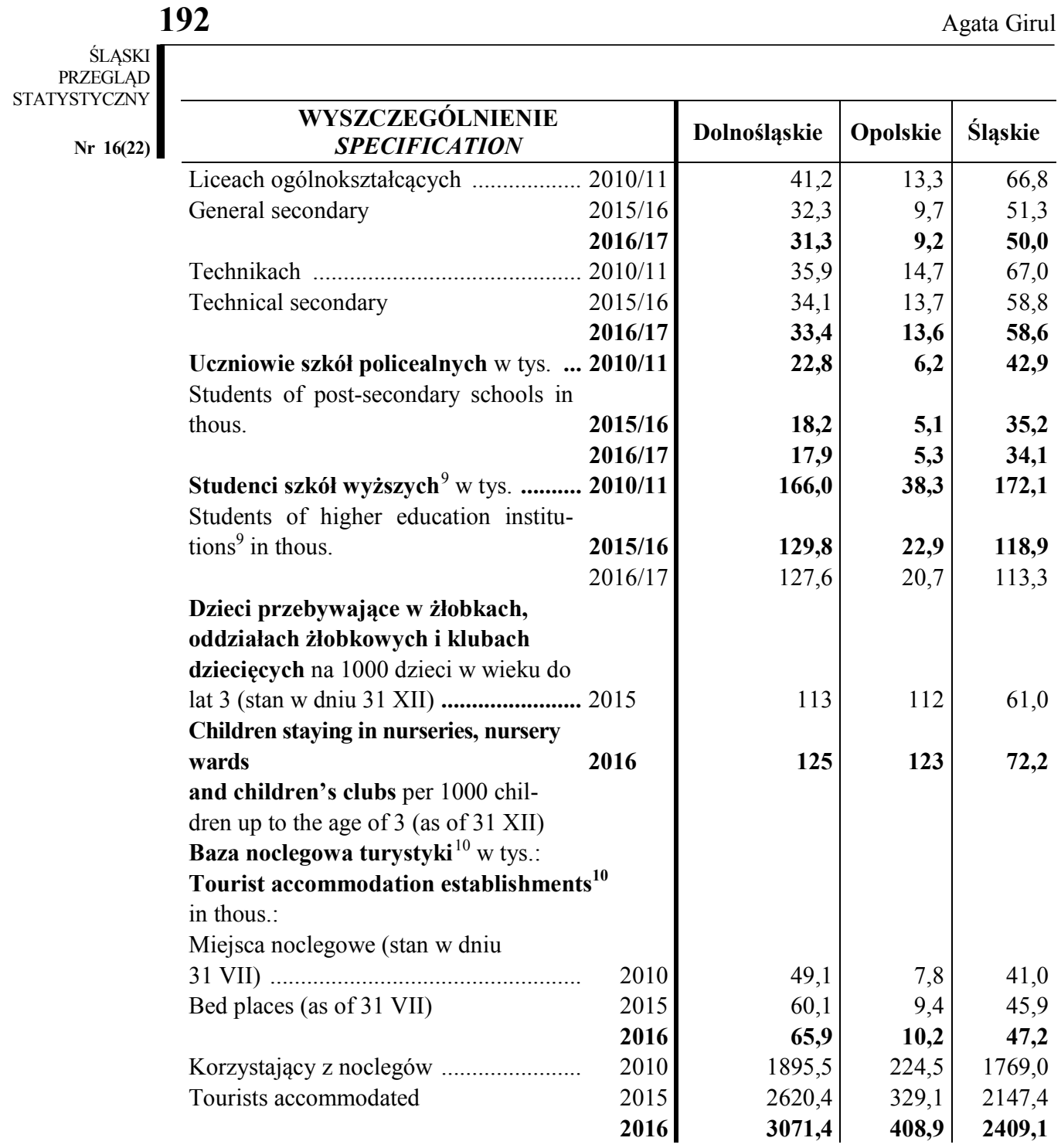

${ }^{9}$ Studentów wykazano zgodnie z siedzibą poszczególnych szkół wyższych łącznie z filiami, zamiejscowymi podstawowymi jednostkami organizacyjnymi, zamiejscowymi ośrodkami dydaktycznymi oraz punktami konsultacyjnymi, bez szkół resortu obrony narodowej oraz resortu spraw wewnętrznych i administracji.

Students are presented according to the place of residence of particular higher education institutions, including branches, non-local basic organisational units, nonlocal didactic centres and consultation points, excluding academies of the Ministry of National Defence and academies of the Ministry of the Interior and Administration.

${ }^{10}$ W latach 2014 i 2015 dotyczy obiektów posiadających 10 i więcej miejsc noclegowych. W $2010 \mathrm{r}$. bez pokoi gościnnych i kwater agroturystycznych.

In 2014 and 2015 data concern establishments possessing 10 and more bed places. In 2010 excluding rooms for rent and agrotourism lodgings. 


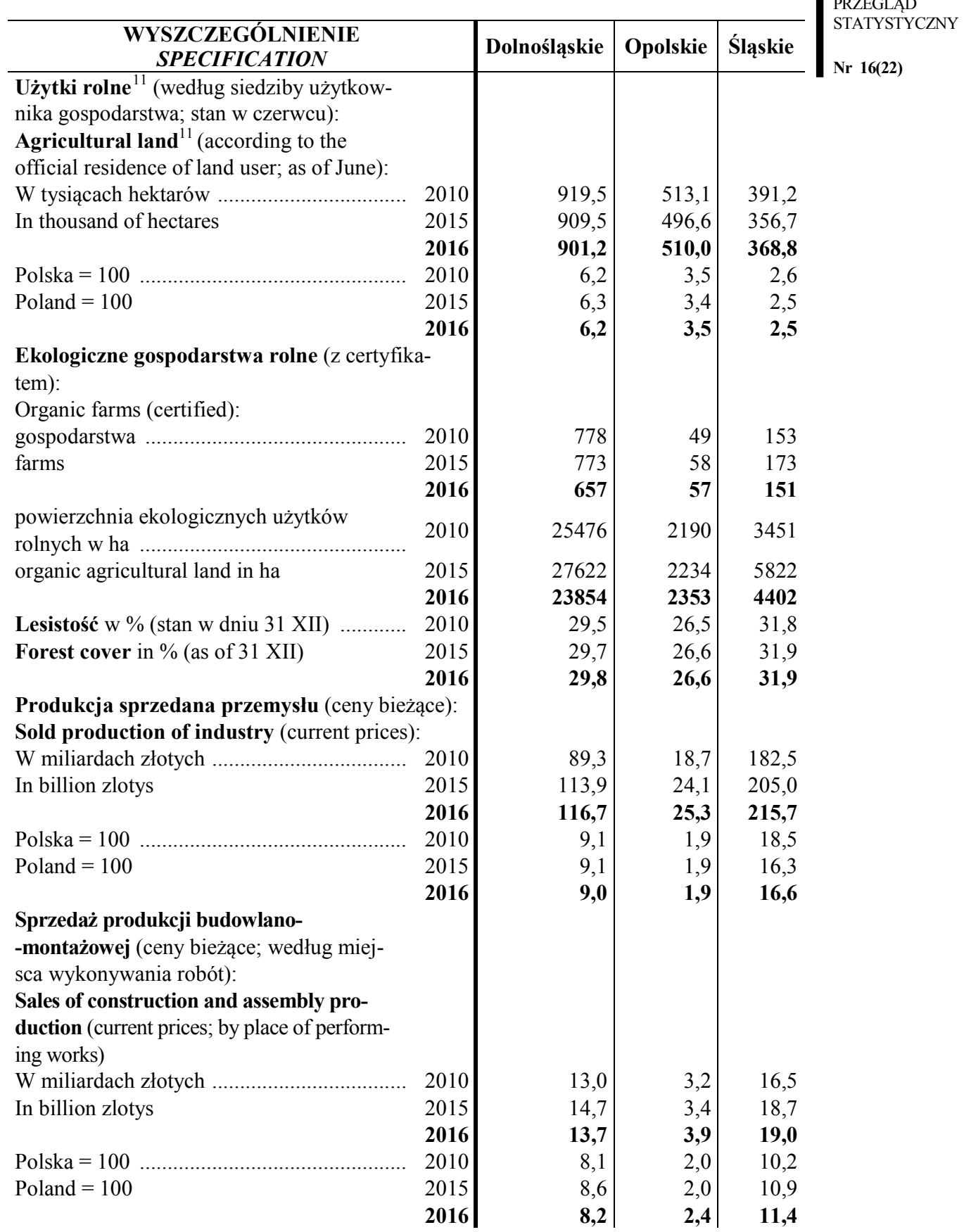

\footnotetext{
${ }^{11}$ W 2010 r. dane Powszechnego Spisu Rolnego.
} In 2010 data of the Agricultural Census. 


\begin{tabular}{|c|c|c|c|c|}
\hline & & & & rata Girul \\
\hline $\begin{array}{r}\text { ŚLASKI } \\
\text { PRZEGLĄD }\end{array}$ & & & & \\
\hline STATYSTYCZNY & $\begin{array}{l}\text { WYSZCZEGÓLNIENIE } \\
\text { SPECIFICATION }\end{array}$ & Dolnośląskie & Opolskie & Śląskie \\
\hline Nr 16(22) & $\begin{array}{l}\text { Liczba ludności na } 1 \text { sklep } \\
\text { (stan w dniu } 31 \text { XII) }\end{array}$ & 106 & 118 & 108 \\
\hline & Population per 1 shop (as of 31 XII) & 104 & 113 & 103 \\
\hline & 2016 & 103 & 121 & 110 \\
\hline & $\begin{array}{l}\text { Wskaźnik cen towarów i usług kon- } \\
\text { sumpcyjnych (rok poprzedni }=100 \text { ) ........... } 2010\end{array}$ & 102,9 & 102,8 & 102,4 \\
\hline & $\begin{array}{l}\text { Price indice of consumer goods and } \\
\text { services }\end{array}$ & 99,2 & 98,9 & 98,8 \\
\hline & $($ previous year $=100)$ & 99,3 & 99,4 & 99,2 \\
\hline & $\begin{array}{l}\text { Produkt krajowy brutto (ceny bieżace): } \\
\text { Gross domestic product (current prices): }\end{array}$ & & & \\
\hline & W miliardach złotych & 123,4 & 31,4 & 186,4 \\
\hline & In billion zlotys & 145,5 & 36,4 & 213,6 \\
\hline & 2015 & 151,7 & $\mathbf{3 7 , 8}$ & 222,8 \\
\hline & Na 1 mieszkańca w tys. zł ........................... 2010 & 42,3 & 30,8 & 40,2 \\
\hline & Per capita in thous. zl & 50,0 & 36,3 & 46,5 \\
\hline & 2015 & 52,2 & 37,8 & 48,7 \\
\hline
\end{tabular}

